\title{
Does Prognostic Nutritional Index Predict Survival in Operated Papilla Vateri Tumors? A Single-centre Experience
}

\author{
Murat Bardakci, Emre Hafizoglu, Fahriye Tugba Kos and Dogan Uncu \\ Department of Medical Oncology, Ankara City Hospital, Ankara, Turkey
}

\begin{abstract}
Objective: To determine the PNI's prognostic effect of prognostic nutritional index (PNI) on operated papilla vateri tumor (PVT) survival.

Study Design: Descriptive study.

Place and Duration of Study: Department of Medical Oncology, Ankara City Hospital, Ankara, Turkey, from April 2003 to December 2020.

Methodology: One hundred and eighty-two patients diagnosed with PVT were retrospectively screened. One hundred and twenty-six non-metastatic patients, who met the inclusion criteria and underwent curative surgery. PNIs were calculated using preoperative albumin and lymphocyte values and the cut-off value was taken and the two groups were compared in terms of overall survival.

Results: The median age of the patients included in the study was 61 (36-88) years; $59.5 \%$ were males. The cut-off value was obtained using ROC-curves for the preoperative PNI values of 126 patients who underwent curative surgery. Patients were divided into two groups as $\mathrm{PNI} \geq 38$ and $\mathrm{PNI}<38$. While median overall survival could not be reached in the group with high PNI, it was 39.3 months in the group with low PNI $(p<0.001)$. In the multivariate cox analysis, PNI elevation was found to be an independent prognostic factor associated with a good prognosis (hazard ratio: $0.18,95 \% \mathrm{Cl}: 0.07-0.48, \mathrm{p}<0.001$ ).
\end{abstract}

Conclusion: In patients with papilla vater tumors, undergoing curative surgery, PNI can play a role as an independent marker in predicting prognosis.

Key Words: Prognostic nutritional index, Papilla vater tumor, Prognosis, Survival.

How to cite this article: Bardakci M, Hafizoglu E, Kos FT, Uncu D. Does Prognostic Nutritional Index Predict Survival in Operated Papilla Vateri Tumors? A Single-centre Experience. J Coll Physicians Surg Pak 2021; 31(12):1428-1432.

\section{INTRODUCTION}

Malignancies occurring $2 \mathrm{~cm}$ around the major papilla in the duodenum are generally defined as periampullary cancers, which include four different anatomical subtypes: pancreatic, ampulla, bile, and duodenal cancers. ${ }^{1}$ PVT is the second most common malignancy among periampullary cancers that following pancreatic head carcinoma. ${ }^{2}$ Although PVT has the best survival compared to other periampullary cancers, the five-year survival ranges from $36.8 \%$ to $78.8 \%$ and has not shown improvement in the last two decades. ${ }^{3}$ Most of the PVT is adenocarcinoma, butsometimesitcan be papillary, adenosquamous, or mucinous.

Correspondence to: Dr. Murat Bardakci, Department of Medical Oncology, Ankara City Hospital, Ankara, Turkey E-mail:dr.muratbardakci@hotmail.com

Received: May 20, 2021; Revised: September 22, 2021; Accepted: November 01, 2021

DOI: https://doi.org/10.29271/jcpsp.2021.12.1428
In addition to classical prognostic parameters, such as lymph node involvement, depth of infiltration, and lymphovascular invasion, the tumor type plays a different role in survival in PVT. ${ }^{4}$ Whipple operation is still the preferred treatment method ${ }^{5}$ and PVT has a relatively better prognosis and higher resection rate compared to periampullary carcinomas. However, most patients present with recurrent disease, partly because of the limited effectiveness of chemotherapy or radiotherapy. In patients with operated PVT, preoperative CA19-9 and bilirubin are well-known markers that are used to predict prognosis. ${ }^{6}$ However, there are inconsistent results in studies conducted with different patient groups. The disadvantage of CA 19-9 and bilirubin values is the low sensitivity and specificity that are seen in patients who develop jaundice. ${ }^{7}$ Therefore, considering the high recurrence rate of PVT, the need for prognostic markers is emphasised. Recently, researchers have identified multiple prognostic factors associated with systemic inflammation in various types of cancer. ${ }^{8}$ These factors include a preoperative neutrophil-lymphocyte ratio (NLR) and platelet-lymphocyte ratio $(\mathrm{PLR})$ as well as serum albumin and C-reactive protein (CRP) levels. 
PNI is an indicator of the nutritional and immunological status of the patients. ${ }^{9}$ There have been many studies showing that PNI is a prognostic factor related to postoperative complications and long-term results in solid cancers such as gastric cancer, colon cancer, and esophageal cancer. ${ }^{10}$ The aim of this study was to determine the prognostic value of PNI and its relationship with overall survival outcomes in patients with operated PVT.

\section{METHODOLOGY}

Between April 2003 and December 2020, 182 patients registered with a diagnosis of PVT, were retrospectively screened. For the Ethics Committee approval of the study, Ankara City Hospital, Ankara, Turkey, No.1 Clinical Research Ethics Committee was consulted and the approval of the Ethics Committee with the study (No. 1737) was obtained on $14 / 04 / 2021$ and was conducted according to the principles of the Declaration of Helsinki (Decision Date: 18.10.2018, Decision No: 2228/2018). One hundred and twenty-six patients, who had histopathologically confirmed PVT and were of 18 years, whose evaluation parameters were reached, and who underwent non-metastatic and curative surgery, were included in the study. The recurrence and progression of the patients were defined using the RECIST (response evaluation criteria in solid tumors) evaluation criteria.

The staging was done according to TNM AJCC UICC, 8th edition, and DFS was defined as the interval between day 1 of surgery and day 1 of relapse or death from any cause, whichever occurs first. OS was defined as the time elapsed from the first day of diagnosis to the date of death from any cause or the last followup date.

Prognostic nutritional index (PNI) was calculated using the formula [(pre-op albumin level $x$ 10) + (pre-op lymphocyte $x$ $0.005)$ ] in all patients. The cut-off value of PNI was found using ROC-curves in patients with PVT who underwent curative surgery. According to this value, the patients were divided into two groups to determine the differences in the properties of the two groups, it was analysed using Pearson Chi-square and Fisher's Exact tests. PASW Statistics Version 25.0 for Windows (SPSSInc., Chicago, IL, USA) was used for all statistical analyses. A value of $p<0.05$ was considered statistically significant. Descriptive statistics are reported as percentages and medians. Survival analysis was performed using the KaplanMeier method. The survival time was determined as $95 \% \mathrm{Cl}$ (confidence interval). Cox regression test was used for multivariate analysis.

\section{RESULTS}

The median age of 126 patients included in the study, who underwent non-metastatic and curative surgery, was 61 $(36-88)$ years, and 75 (59.5\%) of the patients were males and 51 $(40.5 \%)$ were females. ROC curves were used to verify the optimum cut-off value of PNI in patients with operated PVT. The p-value for the area under the ROC curve was $0.01(95 \% \mathrm{Cl}$ : $0.53-0.73$ ) and the best cut-off value was 38.0 with $45.2 \%$ sensi- tivity and $90.6 \%$ specificity. Later, patients were divided into two groups, according to PNI. The median albumin level of patients with high PNI was $3.9(3.8-4.5) \mathrm{g} / \mathrm{L}$, and there was a statistically significant difference with the group with low PNI ( $p$ : 0.001). Table l lists the demographic characteristics and laboratory values of the patients with low and high PNI groups.

Table I: Demographic characteristics and laboratory values of the patients.

\begin{tabular}{|c|c|c|c|}
\hline Patient characteristics & $\begin{array}{c}\text { PNI } \geq 38 \\
n(\%)\end{array}$ & $\begin{array}{c}\text { PNI }<38 \\
\text { n(\%) }\end{array}$ & $\mathbf{p}$ \\
\hline Median age (min-max) & $59(36-76)$ & $62(37-88)$ & $0.21 * * *$ \\
\hline $\begin{array}{l}\text { Gender: } \\
\text { Male } \\
\text { Female }\end{array}$ & $\begin{array}{l}18(51.4) \\
17(48.6)\end{array}$ & $\begin{array}{l}57(62.6) \\
34(37.4)\end{array}$ & $0.25 *$ \\
\hline $\begin{array}{l}\text { Ecog: } † \\
0 \\
1 \\
2 \\
3\end{array}$ & $\begin{array}{c}11(31.4) \\
16(45.7) \\
8(22.9) \\
0(0)\end{array}$ & $\begin{array}{l}22(24.2) \\
39(42.9) \\
27(29.7) \\
3(3.3)\end{array}$ & $0.64 * *$ \\
\hline $\begin{array}{l}\text { Comorbidities: } \\
\text { Diabetes } \\
\text { Hypertension } \\
\text { Coronary artery disease } \\
\text { Asthma-COPDt† }\end{array}$ & $\begin{array}{c}12(34.3) \\
10(28.6) \\
1(2.9) \\
4(11.4)\end{array}$ & $\begin{array}{c}17(18.7) \\
23(25.3) \\
10(11.0) \\
2(2.2)\end{array}$ & $\begin{array}{l}0.06^{*} \\
0.70^{*} \\
0.28^{* *} \\
0.05^{* *}\end{array}$ \\
\hline $\begin{array}{l}\text { Smoking: } \\
\text { Yes } \\
\text { No }\end{array}$ & $\begin{array}{l}16(45.7) \\
19(54.3)\end{array}$ & $\begin{array}{l}39(42.9) \\
52(57.1)\end{array}$ & $0.77^{*}$ \\
\hline $\begin{array}{l}\text { Alcohol: } \\
\text { Yes } \\
\text { No }\end{array}$ & $\begin{array}{c}1(2.9) \\
34(97.1)\end{array}$ & $\begin{array}{c}9(9.9) \\
82(90.1)\end{array}$ & $0.28 * *$ \\
\hline $\begin{array}{l}\text { History of pancreatitis: } \\
\text { Yes } \\
\text { No }\end{array}$ & $\begin{array}{c}2(5.7) \\
33(94.3)\end{array}$ & $\begin{array}{l}11(12.1) \\
80(87.9)\end{array}$ & $0.51^{* *}$ \\
\hline $\begin{array}{l}\text { Symptoms: } \\
\text { Abdominal pain } \\
\text { Jaundice } \\
\text { Weight loss } \\
\text { Itching }\end{array}$ & $\begin{array}{l}23(65.7) \\
18(51.4) \\
6(17.1) \\
6(17.1) \\
\end{array}$ & $\begin{array}{l}45(49.5) \\
62(68.1) \\
18(19.8) \\
19(20.9) \\
\end{array}$ & $\begin{array}{l}0.10^{*} \\
0.08^{*} \\
0.73^{*} \\
0.63^{*}\end{array}$ \\
\hline $\begin{array}{l}\text { Lab values, median: } \\
\text { (min-max) } \\
\text { Total bilirubin (mg/dl) } \\
\text { CEA (ng/mL) } \\
\text { CA } 19-9(\mathrm{U} / \mathrm{mL}) \\
\text { Albumin (g/L) } \\
\text { Lymphocyte (x10^9/L) } \\
\text { Post-op hemoglobin }\end{array}$ & $\begin{array}{c}2.3(0.5-25.0) \\
1.8(0.5-7.1) \\
32.0(0.1-600.0) \\
3.9(3.8-4.5) \\
1.9(0.8-4.5) \\
12.0(8.0-15.3)\end{array}$ & $\begin{array}{c}5.7(0.2-35.1) \\
2,7(0.3-79.0) \\
47.4 \\
(0.8-25744.0) \\
3.4(2.1-3.7) \\
1.7(0.4-4.2) \\
11.8(7.1-15.1)\end{array}$ & $\begin{array}{c}0.16^{* * * *} \\
0.01^{* * * *} \\
0.07^{* * * *} \\
<0.001^{* * * *} \\
0.07^{* * * *} \\
0.49^{* * *}\end{array}$ \\
\hline \multicolumn{4}{|c|}{$\begin{array}{l}\text { *Pearson Chi-Square **Fisher's Exact Test ***Independent Samples ****Mann- } \\
\text { Whitney U-test, CEA: carcinoembryonic antigen, CA19-9: carbohydrate antigen } \\
\text { 19-9, PNI: prognostic nutritional index } \text { Eastern cooperative oncology group, }+\dagger \\
\text { Chronic obstructive pulmonary disease. }\end{array}$} \\
\hline
\end{tabular}

While $57.1 \%$ of the patients in the high PNI group were diagnosed by surgery, $63.3 \%$ of the patients in the low PNI group were diagnosed with ERCP and there was a statistically significant difference between the diagnosis type and PNI (p: 0.004). While the tumor type was polypoid in $82.9 \%$ of the patients in the high PNI group, 57.1\% of the patients in the low PNI group had a polypoid characteristic and the ulcerative type rate was $35.2 \%$, there was a statistically significant difference between the tumor type and PNI (p: 0.023). Table II lists the operation type and tumor characteristics of the patients.

While $70.6 \%$ of patients with high PNI group received adjuvant chemotherapy in operated PVT patients, $84.1 \%$ of patients in the low PNI group received adjuvant chemotherapy. Recurrence and/or progression developed in $22.9 \%$ of patients with high PNI during theirfollow-up, while recurrence and/or progression developed in $72.5 \%$ of patients with low PNI. 
Table II: Operation and tumor characteristics of the patients.

\begin{tabular}{|c|c|c|c|c|c|c|}
\hline & & \multicolumn{2}{|c|}{ PNI $\geq 38$} & \multicolumn{2}{|c|}{$\mathrm{PNi}<38$} & \multirow[b]{2}{*}{$\mathbf{p}$} \\
\hline & & $\mathbf{n}$ & $\%$ & $\mathbf{n}$ & $\%$ & \\
\hline \multirow{3}{*}{ Pre-op drainage } & Percutaneous transhepatic biliary drainage & 4 & $(11.4)$ & 9 & $(9.9)$ & \multirow{3}{*}{$0.56^{*}$} \\
\hline & Endoscopic retrograde biliary drainage & 22 & $(62.9)$ & 59 & $(64.8)$ & \\
\hline & Not done & 8 & $(22.9)$ & 20 & $(22.0)$ & \\
\hline \multirow{3}{*}{ Diagnosis type } & Surgical & 20 & $(57.1)$ & 33 & (36.7) & \multirow{3}{*}{$0.004^{*}$} \\
\hline & Percutaneous biopsy & 2 & $(5.7)$ & 0 & $(0)$ & \\
\hline & Endoscopic retrograde cholangiopancreatography & 13 & $(37.1)$ & 57 & $(63.3)$ & \\
\hline \multirow{4}{*}{ Tumor type } & Polypoid & 29 & $(82.9)$ & 52 & $(57.1)$ & \multirow{4}{*}{$0.02 *$} \\
\hline & Ulcerative & 4 & (11.4) & 32 & $(35.2)$ & \\
\hline & Mix type & 0 & $(0)$ & 1 & $(1.1)$ & \\
\hline & Unknown & 2 & $(5.7)$ & 6 & $(6.6)$ & \\
\hline \multirow{3}{*}{ Tumor sub-type } & Pancreaticobiliary type & 19 & $(54.3)$ & 48 & $(52.7)$ & $0.97 * *$ \\
\hline & Intestinal type & 14 & $(40.0)$ & 37 & $(40.7)$ & \\
\hline & Mix & 2 & $(5.7)$ & 6 & $(6,6)$ & \\
\hline \multirow{3}{*}{ R status } & 0 & 35 & $(100.0)$ & 84 & $(92.3)$ & \multirow{3}{*}{$0.41 *$} \\
\hline & 1 & 0 & (0) & 6 & $(6.6)$ & \\
\hline & 2 & 0 & (0) & 1 & (1.1) & \\
\hline \multirow{2}{*}{ Operation method } & Open & 33 & $(94.3)$ & 89 & $(97.8)$ & \multirow[b]{2}{*}{$0.30 *$} \\
\hline & Laparoscopic & 2 & $(5.7)$ & 2 & $(2.2)$ & \\
\hline \multirow{2}{*}{ Operation type } & Whipple (standard pancreaticoduodenectomy) & 25 & $(71.4)$ & 79 & $(86.8)$ & \multirow{2}{*}{$0.04 * *$} \\
\hline & Pancreaticoduodenectomy sparing pylorus & 10 & $(28.6)$ & 12 & $(13.2)$ & \\
\hline \multirow{4}{*}{ Post-op complication } & Pancreatic fistula & 1 & $(2.9)$ & 3 & (3.3) & \multirow{4}{*}{$0.26 *$} \\
\hline & Hepaticojejunostomy leak & 3 & $(8.6)$ & 7 & $(7.7)$ & \\
\hline & Intraabdominal abscess & 8 & $(22.9)$ & 9 & (9.9) & \\
\hline & No & 22 & $(62.9)$ & 71 & $(78.0)$ & \\
\hline \multirow{3}{*}{ Tumor differentiation } & Well & 10 & $(28.6)$ & 21 & $(23.3)$ & \multirow{3}{*}{$0.21^{* *}$} \\
\hline & Mid & 24 & $(68.6)$ & 57 & $(63.3)$ & \\
\hline & Poor & 1 & $(2.9)$ & 12 & $(13.3)$ & \\
\hline Lymphovascular invasion & & 20 & $(57.1)$ & 61 & $(67.0)$ & $0.29 * *$ \\
\hline Perineural invasion & & 16 & $(45.7)$ & 54 & $(60.0)$ & $0.14 * *$ \\
\hline \multirow{6}{*}{ Stage } & $1 \mathrm{~A}$ & 5 & $(14.3)$ & 2 & $(2.2)$ & \multirow{6}{*}{$0.39 * *$} \\
\hline & $1 \mathrm{~B}$ & 7 & $(20.0)$ & 9 & $(9.9)$ & \\
\hline & $2 \mathrm{~A}$ & 4 & (11.4) & 14 & (15.4) & \\
\hline & $2 \mathrm{~B}$ & 0 & $(0)$ & 0 & (0) & \\
\hline & $3 \mathrm{~A}$ & 13 & (37.1) & 50 & $(54.9)$ & \\
\hline & $3 \mathrm{~B}$ & 6 & $(17.1)$ & 16 & $(17.6)$ & \\
\hline
\end{tabular}

Table III: Factors predicting overall survival in Multivariate Cox regression analysis in operated Papilla Vateri tumors.

\begin{tabular}{|l|l|l|}
\hline & Hr** $(\mathbf{9 5} \% \mathbf{C l})$ & $\mathbf{p}$ \\
\hline Age & $1.02(1.00-1.05)$ & 0.051 \\
\hline Perineural invasion & $0.39(0.21-0.73)$ & 0.003 \\
\hline PNi* & $0.18(0.07-0.48)$ & $<0.001$ \\
\hline$*$ PNI prognostic nutritional index $* *$ Hazard ratio. \\
\hline
\end{tabular}

Patients with high PNI had statistically significantly less recurrence and/or progression compared to patients with low PNI $(p<0.001)$. In the high PNI group, there was statistically significantly less liver recurrence compared to the low PNI group (p: 0.01). In Kaplan-Meier survival analysis, median OS was not reached in the high PNI group, while the median OS was 39.3 (95\% Cl: 15.2-63.5) months in the low PNI group. The difference in OS between the groups was statistically significant $(p<0.001)$ (Figure 1).

In this study, in univariate analysis; gender ( $p: 0.22$ ), age (p: 0.04$)$, comorbidity ( $p: 0.86)$, smoking ( $p: 0.20)$, alcohol use (p: 0.09), Ecog (p: 0.07), jaundice (p: 0.33), pre-op total bilirubin (p: 0.93), pre-op CEA level (p: 0.005), pre-op CA 19-9 (p: 0.01), operation method ( $p: 0.44)$, tumor subtype (p: 0.59), post-op hemoglobin level ( $p: 0.49)$, perineural invasion ( $p: 0.003$ ), lymphovascular invasion ( $p: 0.009)$, PNI $(p<0.001)$ parameters were measured; as shown in Table III.

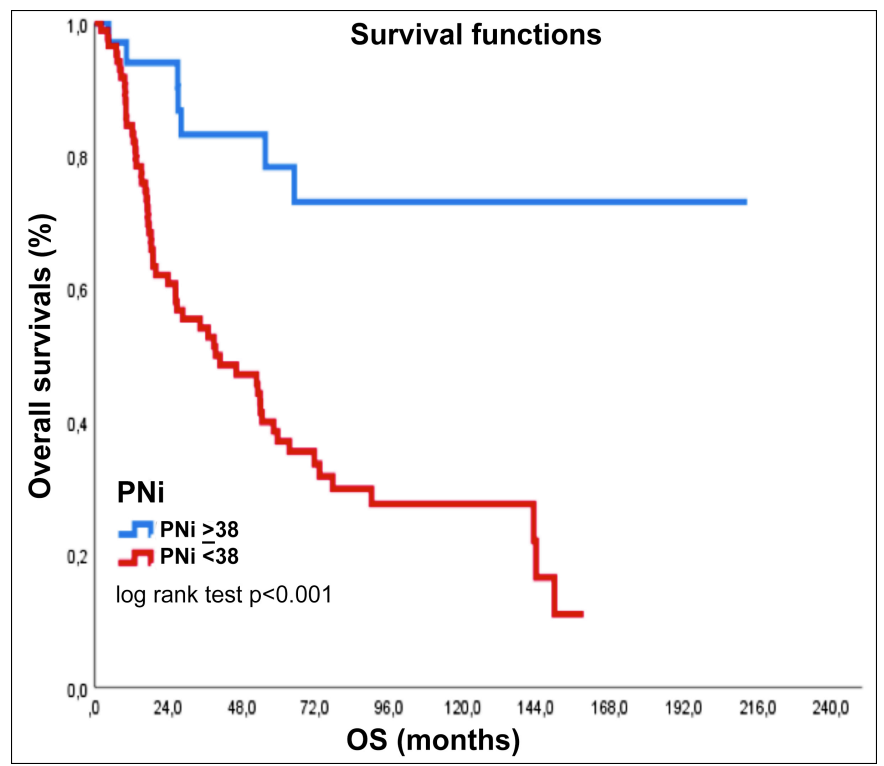

Figure I: Kaplan-Meier survival analysis, PNI $\geq 38$ and $\mathrm{PNI}<38$, PNI: prognostic nutritional index. 
When variables that were significant in univariate analysis were evaluated in multivariate analysis, both PNI perineural invasion were found to be an independent prognostic factor.

\section{DISCUSSION}

In this study, pre-op high PNI values were found that can be an important prognostic marker independent of other risk factors in patients with non-metastatic and operated PVT. The role of prognostic markers based on systemic inflammation has been evaluated in studies performed in different cancers in the last decade. ${ }^{11}$ Factors such as TNM stage, recurrence, and tumor differentiation are used to predict postoperative oncological outcomes in patients with operated PVT. ${ }^{12}$ In this study, age, perineural invasion, lymphovascular invasion, pre-op CEA level, pre-op CA 19-9 level were found to affect survival outcomes in patients with operated PVT. In a study conducted with 104 patients, tumor differentiation was found to be an independent prognostic factor in terms of overall survival in patients with PVT who underwent pancreaticoduodenectomy (PD) ${ }^{13}$ In this study, operated PVT of $88.3 \%$ of patients were found to show good and moderate differentiated tumors. This result may be the reason why the survival outcomes of patients with PVT operated on have a better prognosis compared to other periampullary cancers. In a study conducted with 55 patients, in patients with operated PVT who underwent Whipple resection, perineural invasion is an independent prognostic factor improving postoperative survival. ${ }^{14}$ In the present study, perineural invasion was also found to be an independent factor predicting prognosis in patients with operated PVT (hazard ratio: $0.39,95 \% \mathrm{Cl}: 0.21-0.73, \mathrm{p}: 0.003$ ).

Among the post-resection prognostic factors determined in the studies, pancreatic invasion, lymph node metastasis, and high CA 19-9 level. In a study conducted with patients with PVT undergoing curative resection, age $<60$ years, Cea, CA 19-9, total bilirubin, NLR, PLR, T, and N stages were found to be important prognostic factors for 5 -year OS. ${ }^{15}$ In this study, preoperative CA 19-9 and total bilirubin values did not create a statistically significant difference between patients with high PNI and low PNI in terms of overall survival as shown in the multivariate analysis. When these differences in studies are evaluated together, there is a need for easily accessible, safe biomarkers that predict postoperative prognosis in patients with operated PVT.

In a study conducted on patients with operated PVT, normal albumin and Crp values were found to be associated with longer overall survival. ${ }^{16}$ In this study, in the operated patients with PVT, the median albumin value of the group with high PNI was found to be statistically significantly higher than the group with low PNI $(p=0.001)$. In this study, this is associated with longer survival.

Nutritional status is related to immunological mechanisms and metabolism. A commonly used indicator of nutritional status is PNI, and is calculated using two clinical variables (pre-op albumin and lymphocyte count). ${ }^{17}$ In the present study, the authors examined the relationship of PNI, which is also accepted as a systemic inflammatory response marker, with postoperative overall survival. In a study conducted on patients with operated colorectal cancer, a cut-off value of 45 was taken for PNI using ROC curves; and PNI was found to predict postoperative overall survival. ${ }^{18}$ In another study, the PNI cut-off value in local-advanced pancreatic cancer was taken as the median 47.3, low PNI significantly correlated with shorter OS, and PNI was found to be an independent prognostic factor for $\mathrm{OS} .{ }^{19}$ In a study conducted by taking the PNI cut-off value of 48.85 according to the Contal and O'quigley's method in patients with operated PVT, significant DFS and OS advantage was shown in the high PNI group. ${ }^{20}$ In the present study, PNI cut-off value was found by ROC curves analysis in patients with operated PVT and was taken as 38.0, and the median overall survival was not reached in patients with high PNI. In patients with operated PVT.

It was found that patients with high PNI had a statistically significantly longer median OS than patients with low PNI. These evaluations suggest that survival outcomes in cancer patients do not depend solely on tumor characteristics, but also that predictive markers related to the host play an important role. This study suggests that PNI measured preoperatively in patients with PVT undergoing curative surgery can be considered as an independent prognostic factor. PNI in operated papilla vateri tumors predict postoperative prognosis.

This study has certain limitations. It was retrospective, and done at a single-centre, which had the largest cases. Both albumin and lymphocyte parameters are markers of inflammation and their values may change in cases of acute infection. As these patients were evaluated by the follow-up clinician, it was assumed that there was no evidence of active infection.

\section{CONCLUSION}

Cancer-related inflammation markers are predictors of prognosis and survival in operated papilla of vater tumors, as in other solid tumors. Prognostic nutritional index may be an important marker in predicting prognosis in operated papilla vateri tumors.

\section{ETHICAL APPROVAL:}

Before the commencement of the study, legal and ethical approval was obtained from the Institutional Review Board, Ankara City Hospital, Ankara, Turkey.

\section{PATIENTS' CONSENT:}

All patients signed a document of informed consent.

\section{CONFLICT OF INTEREST:}

The authors declared no conflict of interest. 


\section{AUTHORS' CONTRIBUTION:}

MB: Designed, directed and coordinated the study, created study plan, analysed the data and written the article.

EH, FTK, DU: Selected patients and analysed the data.

\section{REFERENCES}

1. Chandrasegaram MD, Chen JW, Price TJ. Advances in molecular pathology and treatment of Periampullary cancers. Pancreas 2016; 45(1):32-9. doi: 10.1097/MPA.000000000 0000385.

2. Rosenberg R, Friederichs J, Schuster T, Gertler R, Maak M, Becker K, et al. Prognosis of patients with colorectal cancer is associated with lymph node ratio: A single-centre analysis of 3,026 patients over 25 years. Ann Surg 2008; 248(6):968-78. doi: 10.1097/SLA.0b013e318190eddc

3. Talamini MA, Moesinger RC, Pitt HA, Sohn TA, Hruban RH, Lillemoe KD, et al. Adenocarcinoma of the ampulla of Vater: A 28-year experience. Ann Surg 1997; 225(5):590-9. doi: 10.1097/00000658-199705000-00015.

4. Carter JT, Grenert JP, Rubenstein L, Stewart L, W Way L,. Tumors of the ampulla of Vater: Histopathologic classification and predictors of survival. J Am Coll Surg 2008; 207(2):210-18. doi: 10.1016/j.jamcollsurg.2008.01.028.

5. Bhatia S, Miller R, Haddock M, Donohue JH, Krishnan S. Adjuvant therapy for ampullary carcinomas: The mayo clinic experience. Int J Radiat Oncol Biol Phys 2006; 66(2):514-9. doi: 10.1016/j.ijrobp.2006.04.018.

6. Yokoyama N, Shirai Y, Wakai T, Nagakura S, Akazawa K, Hatakeyama $\mathrm{K}$, et al. Jaundice at presentation heralds advanced disease and poor prognosis in patients with ampullary carcinoma. World J Surg 2005; 29(4):519-23. doi: 10.1007/s00268-004-7709-5.

7. Mann DV, Edwards R, Ho S, Lau WY, Glazer G. Elevated tumor marker CA19-9: Clinical interpretation and influence of obstructive jaundice. Eur J Surg Oncol 2000; 26(5): 474-9. doi: 10.1053/ejso.1999.0925.

8. He C, Lin X. Inflammation scores predict the survival of patients with hepatocellular carcinoma who were treated with transarterial chemoembolisation and recombinant human type-5 adenovirus H101. PLoS One 2017; 12(3): e174769. doi: 10.1371/journal.pone.0174769.

9. Sun K, Chen S, Xu J. The prognostic significance of the prognostic nutritional index in cancer: a systematic review and meta-analysis. J Cancer Res Clin Oncol 2014; 140(9): 1537-49. doi: 10.1007/s00432-014-1714-3.
10. Nozoe T, Kohno M, Iguchi T. The prognostic nutritional index can be a prognostic indicator in colorectal carcinoma. Surg Today 2012; 42(6):532-5. doi: 10.1007/s00595-011-0061-0.

11. Guthrie GJ, Charles KA, Roxburgh CS. The systemic inflammation-based neutrophil-lymphocyte ratio: Experience in patients with cancer. Crit Rev Oncol Hematol 2013; 88(1): 218-30. doi: 10.1016/j.critrevonc.2013.03.010.

12. Tomiyasu S, Oda E, Tanaka H. Prognostic factor of carcinoma of the ampulla of vater after surgery. J Clin Oncol 2015; 33(3):270.

13. Lee JW, Choi SB, Lim TW. Prognostic value of the lymph node metastasis in patients with ampulla of Vater cancer after surgical resection. Annals of Hepato-biliary-pancreatic Surgery 2021; 25(1):90-6. doi: 10.14701/ahbps.2021.25. 1.90 .

14. Duffy J. P. Improved Survival for Adenocarcinoma of the Ampulla of Vater. Arch Surg 2003; 138(9): 941. doi: 10.1001/archsurg.138.9.941.

15. Hye rim HA, DoYoun OH, Tae-Yong K. Survival outcomes according to adjuvant treatment and prognostic factors Including host Immune markers in patients with curatively resected ampulla of vater cancer. PLoS One 2016; 11(3):e0151406. doi: 10.1371/journal.pone.0151406.

16. Seo HK, Hwang DW, Lee JH. Role of systemic inflammation in predicting the prognosis of the ampulla of Vater carcinoma. Surgical Oncol 2019; 29: 33-40. doi: 10.1016/j.suronc.2019.02.006

17. Onodera T, Goseki N, Kosaki G. Prognostic nutritional index in gastrointestinal surgery of malnourished cancer patients. Nihon Geka Gakkai Zasshi 1984; 85(9):1001-5.

18. Mohri $Y$, Inoue $Y$, Tanaka K, Hiro J. Prognostic nutritional Index predicts postoperative outcome in colorectal cancer. World J Sur 2013; 37(11): 2688-92. doi: 10.1007/s00268013-2156-9.

19. Geng Y, Qi Q, Sun M. The prognostic nutritional index predicts survival and correlates with the systemic inflammatory response in advanced pancreatic cancer. European J Surgical Oncol 2015; 41(11):1508-14. doi: 10.1016/j.ejso.2015.07.022.

20. Yoo YJ, Kang CM, Choi M. Preoperative prognostic nutritional index as an independent prognostic factor for resected ampulla of Vater cancer. Plos One 2020; 15(3):e0229597. doi: 10.1371/journal.pone.0229597. 